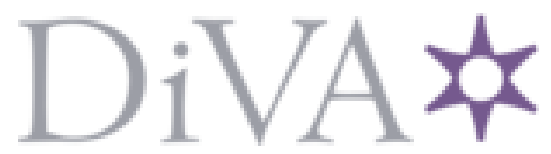

http://www.diva-portal.org

This is the published version of a paper published in Proceedings of IEEE International Conference on Dielectric Liquids.

Citation for the original published paper (version of record):

Ariza, D., Becerra, M., Methling, R., Gortchakow, S., Hollertz, R. et al. (2017)

Influence of Paper Properties on Streamers Creepingin Mineral Oil.

Proceedings of IEEE International Conference on Dielectric Liquids

Access to the published version may require subscription.

N.B. When citing this work, cite the original published paper.

Permanent link to this version:

http://urn.kb.se/resolve?urn=urn:nbn:se:kth:diva-213424 


\section{Influence of Paper Properties on Streamers Creeping in Mineral Oil}

\author{
David Ariza, Marley Becerra \\ Dept. of Electromagnetic Engineering, \\ School of Electrical Engineering \\ Royal Institute of Technology KTH \\ Stockholm, Sweden \\ dfag@kth.se, marley@kth.se
}

\author{
Ralf Methling, Sergey Gortschakow \\ Leibniz Institute for Plasma Science and \\ Technology INP \\ Greifswald, Germany \\ methling@inp-greifswald.de, \\ sergey.gortschakow@inp-greifswald.de
}

\author{
Rebecca Hollertz, Lars Wågberg \\ Division of Fibre Technology, School of \\ Chemical Science and Engineering \\ Royal Institute of Technology KTH \\ Stockholm, Sweden \\ rhollert@kth.se, wagberg@kth.se
}

\begin{abstract}
This work presents an experimental study of second mode positive streamers propagating along mineral oilpaper interfaces. A point-plane arrangement immersed in mineral oil with the paper inclined 60 degrees to the plane electrode is used to create the liquid-solid interface. Kraft paper and a kraft fibril paper, made from cellulosic micro and nano fibrils, with higher density and lower surface roughness are used as the solid materials. High speed shadowgraphy and charge recordings are used to compare the propagation of second mode positive streamers along the mineral oil-kraft paper and mineral oil-kraft fibril paper. Streamers creeping along the mineral oilkraft paper interface propagate mainly into the liquid, with one or two main filaments. In comparison, the streamers propagating along the kraft fibril paper show a strong reduction of the branching; these streamers consist of a single filament that propagates exactly on the solid surface. Streamers along the kraft fibril paper also have longer propagation time than for the case with kraft paper. Mutual electrostatic shielding between filaments is observed for the streamers creeping on the kraft paper. An electrostatic analysis of the influence of permittivity, density and surface roughness of the solid in the electrical properties of the streamer filaments is also performed.
\end{abstract}

Keywords-Streamer; mineral oil; impregnated paper; interface; porosity; roughness

\section{INTRODUCTION}

The electrical prebreakdown phenomena in liquids (usually called 'streamer') is a complex problem that involves several mechanisms, such as electronic, thermal and mechanical [1], [2]. Large number of studies in the literature have been devoted to the understanding of these mechanisms [1]-[3]. Streamer properties and characteristics are highly dependent on the liquid, electrode configurations, pressure, voltage, etc [1], [2], [4]. The large variation of the streamer parameters has made the streamer characterization complicated and today, there is no predictive models of liquid breakdown comparable with the existing ones in the field of gases [1].

Positive streamers is the type of streamers most commonly studied in the literature [1]. They have been classified according with their propagation velocities [1], [4]. The classification comprises four propagation modes. The $1 \mathrm{st}$ mode positive streamer with subsonic speed $(<1 \mathrm{~km} / \mathrm{s})$. The 2 nd mode with a supersonic velocity $(\approx 2 \mathrm{~km} / \mathrm{s})$. The 3 rd and the 4th modes also supersonic with velocities of approximately of $10 \mathrm{~km} / \mathrm{s}$ and $100 \mathrm{~km} / \mathrm{s}$ respectively.
Studies of guided and unguided second mode positive streamers creeping over liquid-solid interfaces include the characterization of some of their main electrical parameters [1]: The potential gradient across the streamer filament [5]-[7], the influence of the thickness and permittivity of the solid on the current of the streamer filament [1], [8], [9] and the influence of the solid materials on the shape of the streamer [10] are some examples. Also, the mechanism of 'self-stabilization' by branching of the streamer in liquids such as mineral oil and alkanes has been shown by experiments with polymeric tubes restricting the streamer branching [11], [12]. Furthermore, the spatial restriction of the streamer branching has been found to decrease the acceleration voltage [11], [12]. The acceleration voltage means the disappearance of 2 nd mode streamers at higher voltages where breakdown is caused by 3 rd or 4 th mode streamers instead [1].

The experimental study reported in this document shows a comparison of 2 nd mode positive streamers creeping along two different types of mineral oil-paper interfaces. Since 2nd mode positive streamers are the most characterized streamer mode [1], they are suitable to study in order to understand which properties of the solid influence the streamer. Kraft paper and kraft fibril paper are used as solids. Both solids are made from kraft pulp. However, the kraft fibrils are pulp fibres further treated, mechanically, in a homogenization process which produces micro and nano sized fibrils and results in papers of higher density and lower surface roughness. This means that the papers have same chemistry but differ in morphology and porosity. In order to investigate the influence of density and surface roughness of the solids on the streamer propagation, charge recordings and high-speed shadowgraphs are used. Velocity, charge, current, propagation time and features of the streamers are also reported. In order to find a correlation between the physical properties of the papers with the electrical properties of the streamer filaments, an evaluation of the model of a single streamer filament introduced in [1], [13] is also performed. This analysis presents a correlation of the circulating current across the streamer filament and its propagation velocity, capacitive coupling to the opposite electrode and applied voltage for a 2 nd mode positive streamer. 


\section{EXPERIMENTAL SETUP}

\section{A. Setup}

The experimental setup consists of a point-plane configuration immersed in mineral oil. The point electrode has a radius $r_{p}$ of $2.9 \mu \mathrm{m}$ and the plane electrode has a diameter of $100 \mathrm{~mm}$. The arrangement is assembled in a test chamber. The point-plane gap distance $d$ is $7 \mathrm{~mm}$. The needle tip is located at the center of the chamber aligned with the lateral viewports. The plane electrode is covered with an impregnated kraft paper with a thickness of $100 \mu \mathrm{m}$ to protect the system in case of breakdown.

A mineral oil-solid interface is made by placing a solid sample in contact with the point electrode. The solid sample is inclined 60 degrees to the plane electrode. Fig. 1 shows an example of a shadowgraph of the needle tip in contact with the surface of the solid sample installed.

A shadowgraph technique is used to detect streamers initiated at the mineral oil-solid interface (e.g. [1], [11], [14][27]). The point electrode tip is illuminated with a laser beam such that a high-speed, 8 frames shadowgraph is recorded with an intensified framing camera (SIM D8-UV, Specialized Imaging). Using a far field microscope (QM 100, Questar corporation / LaVision) the image is projected to the camera sensor. The detected image has a maximum resolution of $4.1 \mu \mathrm{m} /$ pixel.

\section{B. Procedure and sample preparation}

The solid samples are cut into long narrow pieces of $9 \times$ $100 \mathrm{~mm}$. The samples are dried in a vacuum oven $(5 \mathrm{mbar})$ at $105^{\circ} \mathrm{C}$. After $24 \mathrm{~h}$, the temperature in the oven is reduced to 60 ${ }^{\circ} \mathrm{C}$ and filtered mineral oil is inserted into a glass container inside the closed oven through a feedthrough. The oil is degassed for $24 \mathrm{~h}$ in the vacuum oven prior to impregnation of the solid sample.

High voltage square pulses with 35 ns of rise time and 40 $\mu$ s duration are applied to the point-plane arrangement. 100 measurements are performed for a fix voltage of $23.7 \mathrm{kV}$.

\section{Solid samples}

The solid samples are one kraft paper and one paper made from cellulosic micro and nano fibrils. The kraft paper sample is produced from an electrical grade unbleached kraft pulp (Munksjö, Aspa Bruk, Sweden) beaten (mechanically treated) for 4000 revolutions in a PFI-mill while a kraft fibril paper is made from cellulosic micro and nanofibrils produced from the same kraft pulp. The kraft fibrils are prepared, without chemical pre-treatment, by mechanical treatment first by beating the pulp for a total of 6000 revolutions in the PFI- mill followed by homogenization at a pressure of 1600 bar in a Microfluidizer M-110eh (Microfluidics Inc., USA); by three passes through a $400 \mu \mathrm{m}$ and a $200 \mu \mathrm{m}$ chamber connected in series followed by three passes through a $200 \mu \mathrm{m}$ and a $100 \mu \mathrm{m}$ chamber connected in series. Papers from kraft pulp and kraft fibrils are produced using a Rapid Köthen sheet former (PTI, Pettenbach, Austria) according to procedures previously described in [28], [29]. All the investigated samples have a thickness of $100 \mu \mathrm{m}$.

The relative permittivity of the impregnated kraft fibril paper is higher than for the impregnated kraft paper (4.5 and 3.2 respectively) due to its higher density (i.e. lower fraction of mineral oil in the impregnated system).

The surface roughness of the kraft fibril paper is investigated with atomic force microscopy (AFM, Nanoscope IIIa AFM, Bruker AXS). The average roughness of the AFM measurements is defined as the root mean square of the values measured over three different areas $15 \times 15 \mu \mathrm{m}$ in size. The surface roughness of the kraft paper is obtained from frequency analysis of a height map obtained by an OptiTopo (Innventia, Sweden) in which height map is calculated after illumination of the sample surface from low angles from two opposite directions.

Sample properties (relative permittivity, surface roughness and density) are summarized in Table 1 . The thickness used for calculating the paper density are averages from 5 measurements with a disc micrometer (Absolute Digimatic Quick 227, Mitutoyo) of a stack of 3 test pieces (derived from ISO 534:2005).

Table 1. Sample Properties

\begin{tabular}{c|c|c|c}
\hline Material & $\begin{array}{c}\text { Relative } \\
\text { permittivity } \\
\epsilon_{r}\end{array}$ & $\begin{array}{c}\text { Average surface } \\
\text { roughness }(\mathrm{nm})\end{array}$ & $\begin{array}{c}\text { Density } \\
3 \\
\left(\mathrm{~g} / \mathrm{cm}^{3}\right)\end{array}$ \\
\hline Kraft fibril paper & $4.5^{1}$ & 350 & 1.30 \\
Kraft paper & $3.2^{1}$ & 2000 & 0.80 \\
Oil & 2.2 & - & 0.87 \\
\hline
\end{tabular}

\section{RESULTS}

A typical shadowgraph of the propagation of second mode positive streamer creeping along the mineral oil-kraft paper interface is presented in Fig. 1. The streamer propagation along the kraft paper interface shows three main features. First, several and small branches with filamentary appearance start to propagate from the point electrode as it is shown in Fig. 1a and 1b. The length of the branches is in the order of few hundred micrometers. Each filament has some micrometers in diameter and they widen as the streamer propagates. Second, the streamer propagation along the interface consists of either one or two main filaments with small branches Fig. 1c, 1d and 1e. Third, the filaments reach their maximum diameter as soon as the streamer stops propagating (Fig. 1f). The streamer collapse and disconnection of the branches can be observed in Fig. 1g, followed by the fragmentation of the filaments in Fig. 1h. This observation agrees with the dynamic of the filaments of second mode positive streamers reported by other authors [18], [1]. 


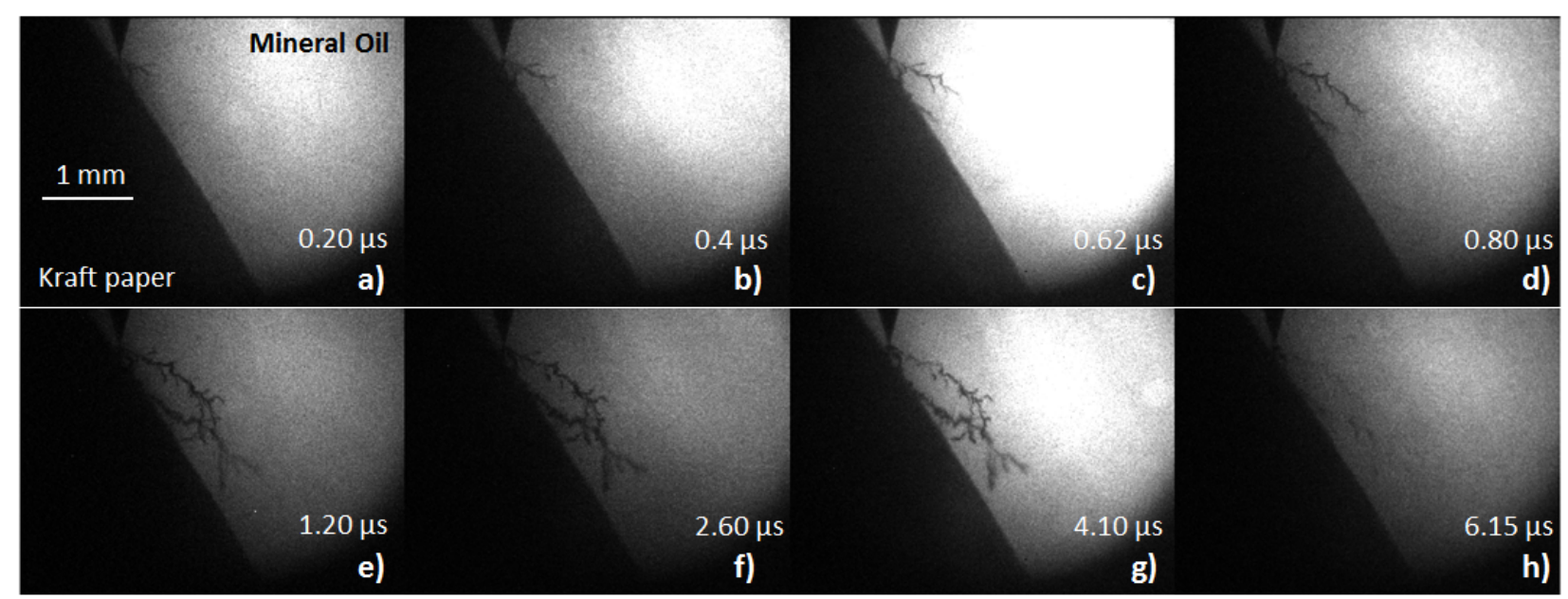

Fig. 1. Shadowgraph of second mode positive streamer propagating along mineral oil-kraft paper interface. Point plane configuration with kraft paper inclined 60 degrees to the plane electrode. $\mathrm{v}=1.57 \mathrm{~km} / \mathrm{s}$.

Fig. 2 shows the charge recording of the streamer propagating along the mineral oil-kraft paper interface reported in Fig. 1. The total charge injected by the streamer is about $1.2 \mathrm{nC}$. The shape of the measured charge indicates a continuous current and its value is about $1 \mathrm{~mA}$. The currents of second mode positive streamer are usually composed by a continuous component with rapid superimposed pulses [30]. The charge injection to the streamer stops after approximately $1.1 \mu \mathrm{s}$ from the voltage rise. This defines the moment when the streamer propagation stops and it corresponds to the shadowgraph shown in Fig. 1e.

Fig. 3 shows an example of the propagation of a second mode positive streamer along the kraft fibril paper interface. The propagation of the streamer along this interface also has three main features. First, small branches with filamentary appearance propagate from the point electrode Fig. 3a, 3b, 3c and $3 \mathrm{~d}$. Their characteristics are similar to those in the case with kraft paper. Second, one of the branches becomes the main filament. Its propagation consists mainly by one filament. The main filament continues its propagation exactly on the paper surface (as seen in Fig. 3e) and possible branches from this filament are strongly reduced. The main filament increases its diameter as the streamer propagates. $78 \%$ of the measurements with kraft fibril paper showed the propagation of the streamer as a single filament along the interface. This behavior of the streamer is not observed in the case of the kraft paper. Third, the streamer reaches its maximum propagation and the process of collapsing, disconnection and fragmentation of the streamer starts (Fig. 3g). Fragments of the main filament remain on the solid surface during the fragmentation process (Fig. 3h).

The charge recording for the streamer propagating along mineral oil-kraft fibril paper in Fig. 3 is shown in Fig. 4. The charge recording shows a linear increase with a maximum injection of charge of $4.8 \mathrm{nC}$. The injection of charge stops after $5.2 \mu$ s when the streamer propagation ends. The shape of the charge recording also suggests that the streamer current is composed mainly of a continuous component of about $1 \mathrm{~mA}$.

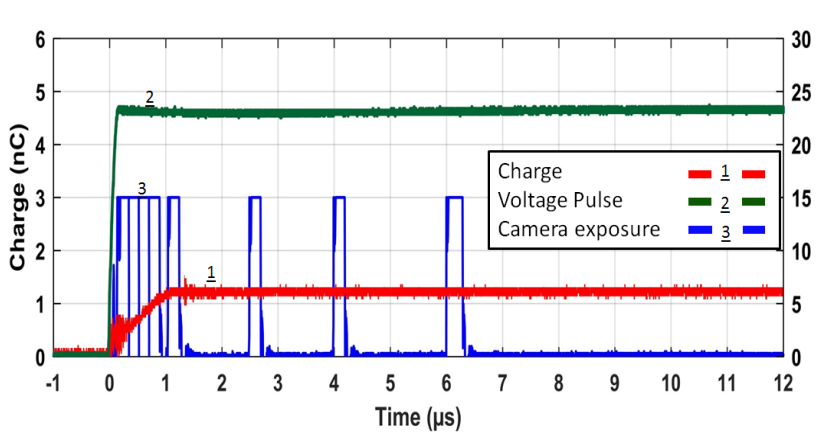

Fig. 2. Charge recordings of second mode positive streamer propagating along mineral oil-kraft paper interface.

Table 2 shows the average values for 100 measurements of the streamer parameters with the kraft paper and the kraft fibril paper. The streamer average velocity is estimated from the streamer length measured in the shadowgraphs and its respective time. The propagation time is assumed as the instant when the streamer charge injection stops. The reported charge in Table 2 corresponds to the average of the maximum charge injected to the streamer when it stops propagating. The average current is obtained from the slope of the charge recordings. No damages of the papers are observed, by optical microscopy, after the streamer propagation.

Table 2. Streamer parameters

\begin{tabular}{c|c|c|c|c|c}
\hline Material & $\begin{array}{c}\text { Velocity } \\
(\mathrm{km} / \mathrm{s})\end{array}$ & $\begin{array}{c}\text { Propagation } \\
\text { time } \\
(\mu \mathrm{s})\end{array}$ & $\begin{array}{c}\text { Number } \\
\text { of } \\
\text { filaments }\end{array}$ & $\begin{array}{c}\text { Charge } \\
(\mathrm{nC})\end{array}$ & $\begin{array}{c}\text { Current } \\
(\mathrm{mA})\end{array}$ \\
\hline $\begin{array}{c}\text { Kraft paper } \\
\text { Kraft fibril } \\
\text { paper }\end{array}$ & $1.52 \pm 0.2$ & 1.78 & 2 & 1.73 & 0.9 \\
\hline
\end{tabular}

\section{DISCUSSION}

The comparison of the cases with kraft paper and kraft fibril paper show two significant observations. First, the streamer propagating with kraft paper have several branches and the streamer propagation has place more into the liquid far from the solid surface. Second, the streamer branching is drastically reduced (almost to a single filament) when it 


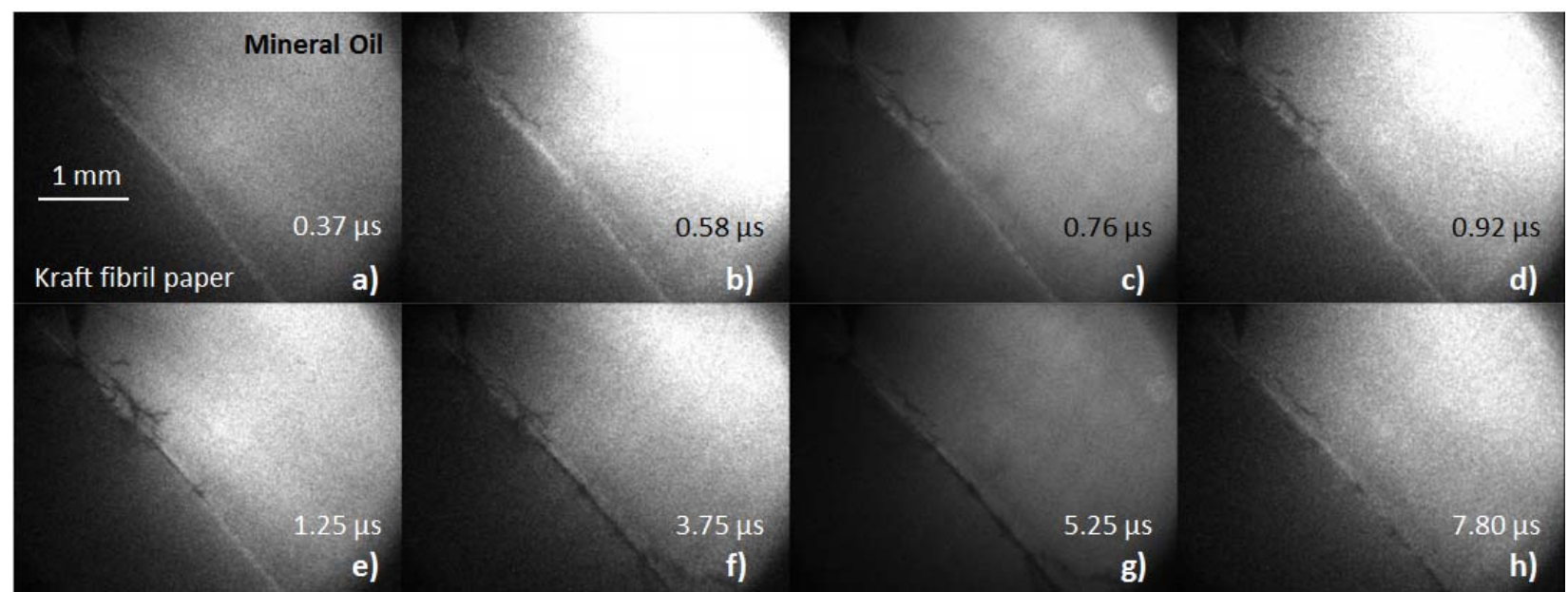

Fig. 3 Shadowgraph of second mode positive streamer propagating along mineral oil-kraft fibril paper interface. Point plane configuration with kraft fibril paper inclined 60 degrees to the plane electrode. $\mathrm{v}=1.68 \mathrm{~km} / \mathrm{s}$.

propagates along the kraft fibril paper; the streamer propagation mostly takes place on the solid surface as a single filament and propagates longer than with kraft paper.

The branches of the streamer creeping along the kraft paper propagate along the interface but with a distance from the solid surface. Please note that the presence of the kraft paper restricts the volume where the streamer can propagate and force the filaments to propagate on the solid, as compared with a case without any solid. The existence of two main filaments with multiple branches in the streamer propagation produces a reduction of the electric field at the head of the filaments due to mutual electrostatic shielding [1], [11], [31], [32]. At atmospheric pressure, the existing potential gradient $E_{s}$ across the streamer filaments during its propagation is the main mechanism responsible of its stopping [1]. This potential gradient also contributes to the reduction of the field at the streamer head until it is lower than the critical electric field $E_{c}$ (i.e $850 \mathrm{MV} / \mathrm{m}$ in mineral oil [33]) for its propagation [1], [6]. Thus, the mutual electrostatic shielding and the increasing potential gradient across the streamer filaments lead to a significant decrease of the streamer propagation time as reported in Table 2. The mean value of the streamer propagation time with kraft paper is $1.78 \mu \mathrm{s}$ which is about $40 \%$ of the propagation time with kraft fibril paper.

The streamers propagating along the mineral oil-kraft fibril paper interface have less branching than those propagating with kraft. Their propagation is mainly guided by one single filament. The presence of the kraft fibril paper also limits the volume where the streamer can propagate. Since the streamer propagation consist mainly of one single filament, no reduction of the field at the head of the filaments due to mutual electrostatic shielding exists [34]. Thus, the stopping of the streamer is caused by the existing potential gradient across the filament responsible of decreasing $E_{c}$ during its propagation [1], [5]. This absence of the mutual electrostatic shielding leads to an increase of the streamer propagation time as it is reported in Table 2. Due to its longer propagation time, the total injection of charge of the streamer is also larger than for the case with kraft paper as shown in Table 2.

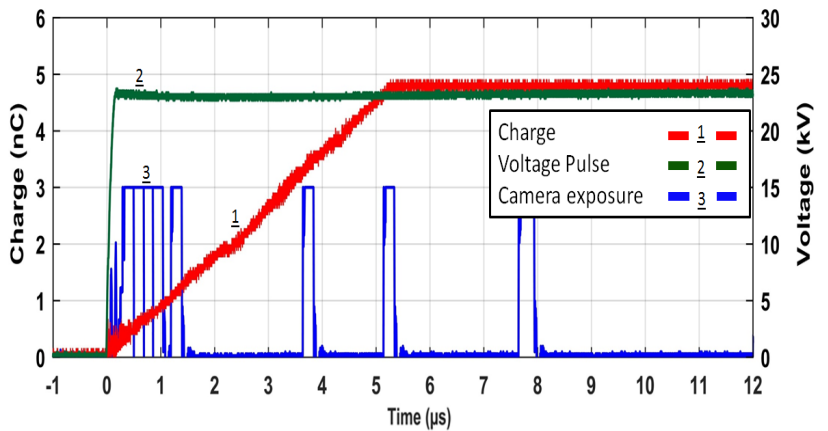

Fig. 4 Charge recordings of second mode positive streamer propagating along mineral oil-kraft fibril paper interface.

When a streamer filament is propagating close to a solid surface, an intensification of the field at the streamer head can occur [1], [7]-[9], [35], [36]. In consequence, the branching of the streamer can be altered [36], [9]. Also, the thickness and permittivity of the solid affects the capacitive coupling of the streamer to the opposite electrode (capacitance per unit of length) [1], [10], [37]. Thus, the differences in streamer branching between the cases with kraft paper and kraft fibril paper could be attributed to differences in permittivity and surface properties of the two solids. Kraft paper is an impregnatable network of fibers where the transition between the oil and the impregnated paper is not well-defined [38]. Kraft paper has a large surface roughness $(2000 \mathrm{~nm})$ which is comparable with the size of the head of the streamer filaments ( $\mu \mathrm{m}$ size [1], [35]) as it is reported in Table 1. When a streamer filament is propagating close to the kraft paper interface, two possible scenarios could occur. One possible scenario is that the streamer is attracted to the solid surface due to intensification of the field between the filament head and the solid surface. This intensification is related to the permittivity mismatch between the mineral oil and the solid [39]. The electric field distribution at the head of the filament is highly modified as it is shown with an electrostatic simulation in Fig. 5a. A second possible scenario is that the intensification of the electric field between the head of the filament and the solid surface is reduced when the streamer reaches a hole filled 


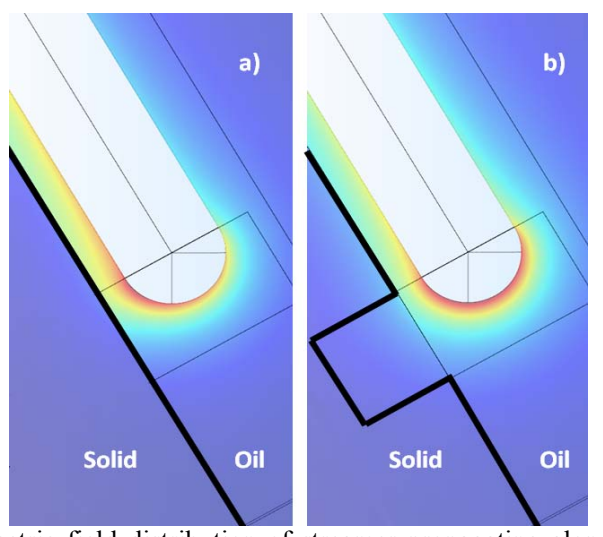

Fig. 5 Electric field distribution of streamer propagating along mineral oil-solid interfaces (normalized scale). a) Case with low surface roughness. b) Case with surface roughness comparable to the streamer head size.

with oil on the solid surface. In this case, the distribution of the field at the head of the filament becomes more symmetrical as it is shown in Fig. 5b. Thus, the next segmentation of the filament can take place either along the solid surface or into the liquid. The propagation of streamers along the surface of the kraft fibril paper, which has lower surface roughness $(350 \mathrm{~nm})$ than kraft paper, follows mainly the first scenario described above.

The velocity of the streamer propagation with kraft paper and with kraft fibril paper is presented in Table 2. Considering the scatter of the data, no significant difference is observed between the respective velocities. Since the streamer velocity is the same with kraft paper and with kraft fibril paper, it is possible to conclude that the streamer velocity is independent of the field across the filament and at the filament head. This conclusion is in agreement with the experimental results in [6] showing that the field intensification at the streamer head due to surface roughness and permittivity mismatch of the solids in the experiment does not influence the streamer velocity for the applied voltage. In small gaps, the velocity of second mode positive streamers is usually almost constant in a large range of applied voltages [34], [40]. Also, the field at the filament head is in the range of $6-10 \times 10^{8} \mathrm{~V} / \mathrm{m}$. An increment in the velocity of the streamer implies a change of propagation mode to $3 \mathrm{rd}$ mode streamer propagation [1], [4]. The 3rd mode is ten times faster than 2nd mode propagation [1], [35], [4]. Third mode propagation has been observed in small gaps and those streamers have fields at the filament head of $15-30 \times 10^{8}$ $\mathrm{V} / \mathrm{m}$ [1], [41]. Thus, the intensification of the field at the filament head at the applied voltage for both paper interfaces does not reach such electric field magnitudes as to change the propagation mode. Thus, the velocity of streamers can be considered independent of the surface roughness and permittivity of the solid surface for the applied voltage level.

It is important to highlight that the permittivity of the kraft paper and kraft fibril paper is related to their respective densities. The denser the paper, the higher is the concentration of polarizable groups [42]. Thus, kraft fibril paper with higher density than kraft paper has higher electrical permittivity (Table 1). A solid with high electrical permittivity increases the capacitive coupling of the streamer filament to the opposite electrode [1], [10]. This increment of the capacitive coupling of the streamer filament results in an increment of the circulating current inside the streamer filament [1], [13]. The influence of the capacitive coupling on the electrical properties of a single streamer filament can be explained with the 'macroscopical' model introduced in [1], [13]. It defines that the current of a streamer filament can be written as [1]:

$$
i=v \frac{d C}{d x} V
$$

The capacitive coupling is shown as the capacitance per unit of length $d C / d x$ of a streamer filament during its propagation. $i$ is the current across the filament, $v$ is the velocity of the streamer filament and $V$ is the voltage applied. The increment of $i$ when $d C / d x$ increases, means that $E_{s}$ decreases. This affirmation agrees with a large number of experiments [1], [7]-[10], [36]. Thus, the permittivity of the solid affects the potential gradient $E_{s}$ across the streamer filament which is the main stopping mechanism [1], [6], [9].

Using the values in Table 2 and (1), it is possible to calculate the capacitance per unit of length of the streamer filament for each solid case. The current per filament is higher for the case with kraft fibril paper which has the highest permittivity. The current is $1.1 \mathrm{~mA}$ and the streamer mainly consists of a single filament. This means that $E_{s}$ is lower for the case with kraft fibril paper and leads to a longer propagation time $4.56 \mu \mathrm{s}$. The capacitance per unit of length of the streamer filament with kraft fibril paper is $28.5 \mathrm{pF} / \mathrm{m}$. For the kraft paper, the mean injected current is $0.9 \mathrm{~mA}$ and the streamers mainly consist of two filaments. Assuming that the filaments are similar, a current of $0.45 \mathrm{~mA}$ is injected for each filament. Since kraft paper has lower current per filament, $E_{s}$ is higher in its streamer filaments. The capacitance per unit of length of each filament is $12.5 \mathrm{pF} / \mathrm{m}$. This leads to a shorter propagation time $1.78 \mu \mathrm{s}$. Thus, streamer filaments propagating along mineral oil-kraft paper interface have lower capacitive coupling and shorter propagation time compared to those ones propagating with kraft fibril paper.

Notice that the total average current injected by streamers is very similar in both cases, with kraft paper and with kraft fibril paper. This seems to be independent of the number of branches of the streamer for the conditions of this experiment. Similar features has been reported in [13]. The average of streamer current does not change significantly for streamers consisted of one to three branches.

\section{CONCLUSIONS}

Streamers propagating along a mineral oil-kraft paper interface propagate with a distance from the solid surface. Their propagation takes place mainly into the liquid. The streamers are mainly composed by two main filaments. The mutual electrostatic shielding between both filaments leads to the decrease of its propagation time and the charge injected.

For the case with the kraft fibril paper, the streamer propagation occurs exactly on the paper surface. The streamer consists mainly of a single filament. The streamer propagation time is longer with kraft fibril paper than with kraft paper. Due 
to the longer propagation time, the final injection of charge is larger than in the case with kraft paper.

Streamers propagating with kraft paper with two main filaments have similar average of injected current than those propagating with kraft fibril paper (with only one main filament). Assuming the both filaments of the kraft paper are similar, the current per filament is lower for the kraft paper case than with kraft fibril paper. This difference is attributed to their difference in electrical permittivity (which is dependent on density) that produces different capacitive coupling of the streamer filaments during their propagation.

Despite their branching differences and current across the streamer filaments, the streamer propagates with same velocity in both solid cases. The streamer velocity is independent of the potential gradient and current across the streamer filament for the applied voltage.

The surface roughness of the solid is correlated to the streamer branching. Due to the high electrical permittivity and low surface roughness of the kraft fibril paper, streamers propagating along the surface have a constant intensification of the field at the head of the streamer filament. This constant field intensification leads the propagation of the streamer exactly along the interface. For solids with high surface roughness as kraft paper, the propagation of the streamer along the interface has two scenarios. The first scenario is when the streamer is attracted to the solid surface due to intensification of the field between the filament head and the solid surface. The second scenario is when the streamer reaches a hole filled with oil on the solid surface, the intensification of the electric field between the head of the filament and the solid surface is reduced. Thus, the next segment of the streamer filament can have place either close to the solid surface or move into the liquid.

\section{ACKNOWLEDGMENT}

The authors would like to acknowledge the financial support of ABB AB Corporate Research, the Swedish Centre for Smart Grids and Energy Storage SweGRIDS, the Swedish strategic research program StandUp for Energy and the EIT Innoenergy Materials platform to the research presented in the document. R. Hollertz also wants to acknowledge the financial support of the Swedish Energy Agency through the Elforsk program. L. Wågberg also acknowledges Walleenberg Wood Science Center for financial support.

\section{REFERENCES}

[1] O. Lesaint, "Prebreakdown phenomena in liquids: propagation 'modes' and basic physical properties," J. Phys. D. Appl. Phys., vol. 49, no. 14, p. 144001, 2016.

[2] A. Denat, "High field conduction and prebreakdown phenomena in dielectric liquids," IEEE Trans. Dielectr. Electr. Insul., vol. 13, no. 3, pp. 518-525, 2006.

[3] A. Denat, "Conduction and breakdown initiation in dielectric liquids," in 2011 IEEE International Conference on Dielectric Liquids, 2011, vol. 22, no. 9, pp. 1-11

[4] A. Beroual, M. Zahn, A. Badent, K. Kist, A. J. Schwabe, H. Yamashita, K. Yamazawa, M. Danikas, W. D. Chadband, and Y. Torshin, "Propagation and structure of streamers in liquid dielectrics," IEEE Electr. Insul. Mag., vol. 14, no. 2, pp. 6-17, 1998.

[5] A. Saker and P. Atten, "Potential distribution along single negative creeping streamer in transformer oil," IEE Proc. A Sci. Meas. Technol., vol. 140 , no. 5 , p. $375,1993$.

[6] A. Saker and P. Atten, "Properties of streamers in transformer oil," IEEE Trans. Dielectr. Electr. Insul., vol. 3, no. 6, pp. 784-791, 1996.

[7] R. Hanaoka, T. Kohrin, T. Miyagawa, and T. Nishi, "Creepage discharge characteristics over solid-liquid interfaces with grounded side electrode," IEEE Trans. Dielectr. Electr. Insul., vol. 9, no. 2, pp. 308$315,2002$.

[8] L. Kebbabi and A. Beroual, "Optical and electrical investigations on creeping discharges over solid/liquid interfaces under impulse voltage," IEEE Int. Conf. Dielectr. Liq. 2005 ICDL 2005, pp. 127-130, 2005.

[9] A. Beroual, V. H. Dang, M. L. Coulibaly, and C. Perrier, "Investigation on creeping discharges propagating over pressboard immersed in mineral and vegetable oils under AC, DC and lightning impulse voltages," IEEE Trans. Dielectr. Electr. Insul., vol. 20, no. 5, pp. 16351640, 2013.

[10] A. Beroual and L. Kebbabi, "Influence of the voltage waveform and hydrostatic pressure on morphology and final length of discharges propagating over solid-liquid interfaces," in IEEE Transactions on Dielectrics and Electrical Insulation, 2009, vol. 16, no. 6, pp. 1574 1581 .

[11] G. Massala and O. Lesaint, "Positive streamer propagation in large oil gaps: electrical properties of streamers," IEEE Trans. Dielectr. Electr. Insul., vol. 5, no. 3, pp. 371-381, 1998.

[12] N. V. Dung, D. Linhjell, L. E. Lundgaard, H. K. Hoidalen, and M. Unge, "Effects of spatial restriction on streamers in white oil," in Proceedings of the 2014 IEEE 18th International Conference on Dielectric Liquids, ICDL 2014, 2014.

[13] O. Lesaint, P. Gournay, and R. Tobazeon, "Investigations on transient currents associated with streamer propagation in dielectric liquids," IEEE Trans. Electr. Insul., vol. 26, no. 4, pp. 699-707, 1991.

[14] C. T. Duy, O. Lesaint, a Denat, and N. Bonifaci, "Streamer propagation and breakdown in natural ester at high voltage," IEEE Trans. Dielectr. Electr. Insul., vol. 16, no. 6, pp. 1582-1594, 2009.

[15] A. Beroual, M. Zahn, A. Badent, K. Kist, A. J. Schwabe, H. Yamashita, K. Yamazawa, M. Danikas, W. D. Chadband, and Y. Torshin, "Propagation and structure of streamers in liquid dielectrics," IEEE Electr. Insul. Mag., vol. 14, no. 2, pp. 6-17, Mar. 1998.

[16] S. Ingebrigtsen, L. E. Lundgaard, and P.-O. Åstrand, "Effects of additives on prebreakdown phenomena in liquid cyclohexane: II. Streamer propagation," J. Phys. D. Appl. Phys., vol. 40, no. 18, pp. 5624-5634, 2007.

[17] S. Ingebrigtsen, L. E. Lundgaard, and P.-O. Åstrand, "Effects of additives on prebreakdown phenomena in liquid cyclohexane: I. Streamer initiation," J. Phys. D. Appl. Phys., vol. 40, no. 17, pp. 51615169, Sep. 2007.

[18] P. Gournay and O. Lesaint, "On the gaseous nature of positive filamentary streamers in hydrocarbon liquids. II: Propagation, growth and collapse of gaseous filaments in pentane," J. Phys. D. Appl. Phys., vol. 27, no. 10, pp. 2117-2127, 1999.

[19] R. Kattan, a Denat, and O. Lesaint, "Generation, growth, and collapse of vapor bubbles in hydrocarbon liquids under a high divergent electric field,” J. Appl. Phys., vol. 66, no. 9, pp. 4062-4066, 1989.

[20] Y. Tsunoda and S. Ohgaki, "A study of positive streamer growth under surface discharge configuration in liquid paraffin," no. 6, pp. 594-601, 1984.

[21] L. Dumitrescu, N. Bonifaci, A. Denat, P. Notinghe, L. U. J. Fourier, and A. Martyrs, "Study of Streamer Inception under Impulse Voltage in Liq , uid Cyclohexane," pp. 300-303, 2000.

[22] L. Dumitrescu, O. Lesaint, N. Bonifaci, a Denat, and P. Notingher, "Study of streamer inception in cyclohexane with a sensitive charge measurement technique under impulse voltage," J. Electrostat., vol. 53, no. 2, pp. 135-146, 2001.

[23] J. Nieto-Salazar, O. Lesaint, and a Denat, "Transient current and light emission associated to the propagation of pre-breakdown phenomena in water," 2003 Annu. Rep. Conf. Electr. Insul. Dielectr. Phenom., pp. 542-545, 2003.

[24] L. Costeanu and O. Lesaint, "On mechanisms involved in the propagation of subsonic positive streamers in cyclohexane," Dielectr. 
Liq. 2002. ICDL 2002. Proc. 2002 IEEE 14th Int. Conf., no. Icdl, pp. 143-146, 2002.

[25] H. Yamashita, H. Kawai, K. L. Stricklett, and E. F. Kelley, "The effect of high pressure on prebreakdown phenomena in n-hexane," in 10th International Conference on Conduction and Breakdown in Dielectric Liquids, 1990, vol. 20899, pp. 404-409.

[26] M. Unge, S. Singha, N. Van Dung, D. Linhjell, S. Ingebrigtsen, and L. E. Lundgaard, "Enhancements in the lightning impulse breakdown characteristics of natural ester dielectric liquids," Appl. Phys. Lett., vol. 102, no. 17, p. 172905, 2013.

[27] Y. Nakao, M. Naruse, T. Sakai, H. Itoh, Y. Suzuki, Y. Sakai, and H. Tagashira, "Propagation characteristics of impulse creepage discharge in a parallel-plane gap with a protruding point in transformer oil," Electr. Eng. Japan, vol. 124, no. 2, pp. 1-7, 1998.

[28] H. Sehaqui, A. Liu, Q. Zhou, and L. A. Berglund, "Fast preparation procedure for large, flat cellulose and cellulose/inorganic nanopaper structures," Biomacromolecules, vol. 11, no. 9, pp. 2195-2198, 2010.

[29] R. Hollertz, L. Wågberg, and C. Pitois, "Effect of composition and Morphology on the dielectric response of cellulose-based electrical insulation," IEEE Trans. Dielectr. Electr. Insul., vol. 22, no. 4, pp. 2339-2348, 2015.

[30] P. Gournay and O. Lesaint, "A study of the inception of positive streamers in cyclohexane and pentane," J. Phys. D. Appl. Phys., vol. 26, no. 11, pp. 1966-1974, 1993.

[31] O. Lesaint, A. Denat, and F. Mc Cluskey, "Positive streamers in short and large gaps in hydrocarbons of various chemical natures," Proc. 2014 IEEE 18th Int. Conf. Dielectr. Liq. ICDL 2014, pp. 3-6, 2014.

[32] N. Dung, H. Hoidalen, D. Linhjell, L. Lundgaard, and M. Unge, "Influence of impurities and additives on positive streamers in paraffinic model oil," IEEE Trans. Dielectr. Electr. Insul., vol. 19, no. 5, pp. 1593-1603, Oct. 2012.

[33] O. Lesaint and T. V. Top, "Streamer initiation in mineral oil. Part I:
Electrode surface effect under impulse voltage," IEEE Trans. Dielectr. Electr. Insul., vol. 9, no. 1, pp. 84-91, 2002.

[34] T. V. Top, G. Massala, and O. Lesaint, "Streamer propagation in mineral oil in semi-uniform geometry," IEEE Trans. Dielectr. Electr. Insul., vol. 9, no. 1, pp. 76-83, 2002.

[35] O. Lesaint and G. Massala, "Positive streamer propagation in large oil gaps: experimental characterization of propagation modes," IEEE Trans. Dielectr. Electr. Insul., vol. 5, no. 3, pp. 360-370, Jun. 1998.

[36] L. Kebbabi and A. Beroual, "Optical and electrical characterization of creeping discharges over solid/liquid interfaces under lightning impulse voltage," in IEEE Transactions on Dielectrics and Electrical Insulation, 2006, vol. 13, no. 3, pp. 565-571.

[37] A. Beroual and L. Kebbabi, "Influence of Capacitive Effects on the Characteristics of Creeping Discharges Propagating over Solid/Liquid Interfaces under Impulse Voltages," in 2008 Annual Report Conference on Electrical Insulation and Dielectric Phenomena, 2008, pp. 357-360.

[38] P. M. Mitchinson, P. L. Lewin, B. D. Strawbridge, and P. Jarman, "Tracking and surface discharge at the oil-pressboard interface," IEEE Electr. Insul. Mag., vol. 26, no. 2, pp. 35-41, 2010.

[39] R. J. Taylor, "Effect of permittivity matching on the flashover of solid/liquid interfaces," Proc. Inst. Electr. Eng., vol. 124, no. 10, p. 899, 1977.

[40] O. Lesaint and F. Roldan, "On the correlation between positive streamer shape and propagation," Dielectr. Liq. 1999. (ICDL '99) Proc. 1999 IEEE 13th Int. Conf., no. figure 2, pp. 167-170, 1999.

[41] S. Sakamoto and H. Yamada, "Optical Study of Conduction and Breakdown in Dielectric Liquids," IEEE Trans. Electr. Insul., vol. EI15, no. 3, pp. 171-181, Jun. 1980.

[42] R. Hollertz, D. Ariza, C. Pitois, and L. Wågberg, "Dielectric response of kraft paper from fibres modified by silica nanoparticles," Апnu. Rep. - Conf. Electr. Insul. Dielectr. Phenomena, CEIDP, vol. 2015-Decem, pp. 459-462, 2015. 